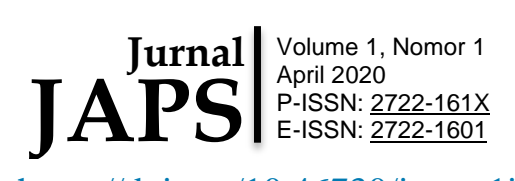

DOI: https://doi.org/10.46730/japs.v1i1.10

\title{
Fungsi Instruktif, Konsultatif, Partisipatif dan Delegasi Dalam Melihat Fungsi Kepemimpinan Kepala Desa Kelapapati Kabupaten Bengkalis
}

\author{
${ }^{1}$ Dedy Afrizal; ${ }^{2}$ Riko Saputra; ${ }^{3}$ Lilis Wahyuni, ${ }^{4}$ Erinaldi
}

\begin{tabular}{ll}
\hline Kata kunci & Abstrak \\
Kepemimpinan, & Permasalahan penelitian ini berkaitan dengan adanya fenomena \\
Partisipatif, & kepemimpinan pada pemerintahan Desa Kelapapati sehingga \\
Delegasi, & Desa, \\
Kepala Desa & peneliti tertarik untuk menganalisis lebih mendalam tentang fungsi \\
& kepemimpinan dengan tujuan Penelitian untuk menganalisis \\
& pemerintahan Desa Kelapapati dilihat dari fungsi instruktif, \\
& konsultatif, partisipatif dan delegasi. Metode penelitian yang \\
& digunakan mengunakan pendekatan campuran kualitatif dan \\
& kuantitatif dengan metode pengumpulan data observasi, wawancara, \\
& kuesioner. Temuan penelitian dalam menjawab pertanyaan \\
& bagaimana fungsi kepemimpinan Kepala Desa belum berjalan \\
& dengan optimal, karena masih rendah kesadaran aparatur desa dan \\
& masyarakat dalam melaksanakan perintah yang diberikan kepala \\
& desa serta kurangnya kehadiran aparatur, lembaga kemasyarakatan \\
& dan masyarakat dalam mengikuti kegiatan Desa. Sedangkan \\
& jawaban sejauh mana fungsi kepemimpinan Kepala Desa secara \\
& kuantitatif ditemukan penelitian tentang pelaksanaan fungsi \\
& kepemimpinan didesa Kelapapati adalah cukup baik.
\end{tabular}

Keywords

Leadership, participatory, delegation, village, village head

\begin{abstract}
The problem of this research is related to the leadership phenomenon in the village government of Kelapapati so that researchers are interested to analyze more in-depth about leadership functions with research objectives to analyse how and how far the village head functions in Kelapapati Village government activities are seen from instructive functions, consultative, participatory and delegation. The study method used to use a qualitative and quantitative mixture approach with observation data collection methods, interviews, questionnaire. Research findings in answering the question of how the leadership function of the village head has not run optimally, because it is still a low awareness of village apparatus and society in carrying out orders given by the village head as well as lack of presence apparatus, Community institutions and communities in following the activities of the village. Meanwhile, the answer to how far the leadership function of village head is quantitatively found research on implementing leadership functions in Kelapapati village is good enough.
\end{abstract}

\section{Pendahuluan}

Salah satu unsur penting dalam sistem pembangunan daerah adalah penyelenggaraan pembangunan yang berpusat di desa. Desa merupakan pelaksana pembangunan garis depan dalam Pemerintahan Indonesia. Dibutuhkannya seorang pemimpin yang dapat merealisasikan pembangunan tersebut. Pemimpin menurut Kartono (2005) adalah “ seorang pribadi yang 
memiliki superioritas tertentu, sehingga dia memiliki kewibawaan dan kekuasaan untuk menggerakkan orang lain melakukan usaha bersama guna mencapai sasaran tertentu". Sedangkan, Rivai dalam Pasalong (2008) mengatakan“ anggota dari suatu kumpulan yang diberi kedudukan tertentu dan diharapkan dapat bertindak sesuai kedudukannya". Terlihat jelas bahwa pemimpin merupakan seseorang yang diharapkan dapat mengendalikan ke arah yang diinginkan dengan kekuasaannya.

Desa merupakan organisasi publik dasar di tingkat administrasi yang menjadi ikon dalam pengembangan dan peningkatan kesejahteraan masyarakat (Syofian \& Ricky, 2019). Pemimpin didesa disebut sebagai "kepala desa" diberikan fungsi dalam pemerintahan untuk menjalankan masyarakatnya dalam mencapai tujuan desa. Kepala desa menjalankan fungsi kepemimpinannya atas dasar diterbitkannya Undang-Undang Nomor 06 Tahun 2014 tentang Pemerintahan Desa dan ditetapkannya Peraturan Pemerintah Nomor 43 Tahun 2014 tentang peraturan pelaksanaannya yang merupakan pedoman dalam penyelenggaraan pemerintahan Desa (Harfis, Sopyan, \& Afrizal, 2019; Syofian \& Ricky, 2019).

Kepemimpinan kepala desa juga dijalankan di Desa Kelapapati Kabupaten Bengkalis. Berdasarkan Peraturan Daerah Kabupaten Bengkalis Nomor 04 Tahun 2008 tentang rincian tugas dari pemerintah Desa Kelapapati sebagai dasar kepala desa menjalankan kepemimpinannya. Kepala desa memiliki fungsi penting dalam menjalankan roda pemerintahan dan pembangunan di desa (Syafitri \& Suriani, 2019). Kepala desa harus mampu merencanakan dan membuat suatu keputusan untuk dipergunakan dalam menjalankan roda pemerintahan desa, sehingga pemerintahan desa dapat berjalan sebagaimana mestinya. Disamping itu, dalam menjalankan kepemimpinannya, kepala desa sebagai pemimpin formal dapat menjadi motivator, fasilitator dan mediator dan sebagai penentu keberhasilan semua program dan perencanaan pembangunan yang telah direncanakan (Lamangida, Akbar \& Hasan, 2017). Sementara Manua, Sumampow \& Kasenda (2017) mengatakan bahwa tugas kepala desa menjalankan pemerintahan desa seperti Pembangunan Desa, pembinaan kemasyarakatan, pemberdayaan masyarakat Desa. Kepala desa juga di tuntut untuk menjalankan fungsi kepemimpinannya dalam semua aktivitas pemerintahan desa. Hal ini dipertegas oleh Nurhasanah (2018) yang mengatakan bahwa kepala desa hendaknya menerapkan nilai-nilai lokal dalam bentuk pelayanan publik, yaitu berupa penyediaan barang dan layanan publik, pelayanan pembangunan, pelayanan perlindungan dalam memberikan rasa aman dan tentram kemasyarakatnya. Untuk membuat keputusan, Kepala Desa harus mempertimbangkan pendapat-pendapat dari aparatur dan masyarakatnya, agar keputusan yang dibuat dapat diterima secara bersama.

Berdasarkan observasi, masih rendahnya tingkat kesadaran aparatur desa dan masyarakat dalam melaksanakan arahan dan perintah yang diberikan oleh Kepala Desa. Permasalahan ini kerap terjadi di sebuah desa, seperti di Sukorejo (Amrulloh \& Pramusinto, 2017) mengatakan kepemimpinan kepala desa se- Kecamatan Sukorejo masih kurang disebabkan karena kepala desa kurang memberikan karya, karsa, maupun gagasan. Sementara itu, kepala desa kelapapati dituntut untuk mampu berkoordinasi dengan cara mengadakan musyawarah dalam membuat keputusan. Sesuai dengan Undang-Undang Nomor 6 Tahun 2014 di dalamnya menjelaskan tentang musyawarah desa atau dengan nama lain musyawarah antara Badan Permusyawaratan Desa, Pemerintah Desa, unsur masyarakat yang 
diselenggarakan oleh Badan Permusyawaratan Desa dalam menyepakati hal yang bersifat strategis (Indonesia, 2014).

Rendahnya kehadiran aparatur, lembaga kemasyarakatan dan masyarakat dalam mengikuti kegiatan rapat rutin yang diadakan Desa kelapapati dalam membuat rencana kegiatan-kegiatan pembangunan juga menggambarkan bahwa masih belum maksimalnya pelaksanaan kepemimpinan yang dilaksanakan kepala desa. Hal ini penting, sebab Yanuar \& Dandang Setyawanti (2017) mengatakan bahwa kepemimpinan kepala desa berpengaruh terhadap kepatuhan masyarakat desanya. Padahal, dalam prakteknya perlu partisipasi dari seluruh unsur aparatur desa dan masyarakat dalam aktivitas dan kegiatan desa sehingga menghasilkaan keputusan yang baik. Permasalahan partisipasi ini juga di tegaskan penelitian Harfis, Sopyan, \& Afrizal (2019) mengatakan faktor penghambat dalam partisipasi masyarakat yaitu kurangnya keterlibatan dalam mengamankan hasil pembangunan, memelihara serta memanfaatkan hasil pembangunan dan mengembangkan hasil pembangunan tersebut untuk meningkatkan kesejahteraan masyarakat desa. Hal ini senada dengan pendapat Mahayana (2013) mengatakan peran kepala desa yang paling sering terlihat atau peran yang paling menojol yaitu sebagai fasilitator hal ini terlihat bahwa Kepala Desa sering memfasilitasi setiap kegiatan-kegiatan pembangunan desa di Desa

Kepemimpinan Kepala Desa merupakan faktor terpenting untuk kemajuan dan perkembangan desa (Manua et al., 2017). Kepemimpinan kepala desa dalam mencapai tujuan desanya sangat diperlukan. Menurut (Fahmi, 2012) menyatakan kepemimpinan adalah sebuah keahlian dalam mempengaruhi dan mengarahkan orang lain kepada pencapaian tujuan. Sedangkan (Pasalong, 2008) mengatakan " fungsi kepemimpinan dapat tinjau dari: 1. Fungsi Perintah yaitu fungsi kepemimpinan yang bersifat satu arah kepada yang dipimpinnya, 2. Fungsi Konsultatif, yaitu fungsi kepemimpinan yang bersifat dua arah kepada yang dipimpinnya, meskipun pelaksanaan sangat tergantung pada pihak pemimpin, 3. Fungsi Partisipatif, yaiu fungsi kepemimpinan yang bersifat dua arah kepada yang dipimpinnya, tetapi juga berwujud pelaksanaan hubungan manusia yang efektif antara pemimpin dan yang dipimpin, 4. Fungsi Delegasi, yaitu fungsi pemimpin untuk mendelegasikan wewenang untuk membuat, menetapkan, dan atau melaksanakan keputusan, baik melalui persetujuan maupun tanpa persetujuan pimpinan. Berdasarkan uraian tersebut, dirumuskan tujuan bagaimana fungsi instruktif, konsultatif, partisipatif dan delegasi dalam melihat fungsi kepemimpinan kepala desa Kelapapati Kabupaten Bengkalis.

\section{Metode}

Penelitian dilakukan didesa Kelapapati Kabupaten Bengkalis menggunakan pendekatan kuantitatif dengan menyajikan secara statistik deskriptif. Kuesioner disebarkan sebanyak 100 responden yang terdiri dari Kepala desa, Sekretaris desa, Kepala Urusan, Staf Desa, Pengurus BPD, LKMD, Kepala Dusun, RT dan RW serta masyarakat disetiap dusun dengan tehknik Quota sampling. Pertimbangan utama dalam mengarahkan pengambilan sampel kuota adalah kemudahan akses peneliti, karakteristik yang relevan terhadap suatu penelitian (Kumar, 2019). Analisa data menggunakan pengukuran rating scale. 


\section{Hasil dan Pembahasan}

1. Fungsi Instruktif

Kepala desa memiliki fungsi instruktif dalam memberikan perintah dan arahan hal ini sesuai dengan Pasalong (2008) mengatakan Fungsi Instruktif adalah "Fungsi kepemimpinan yang bersifat satu arah kepada yang dipimpinnya. Pemimpin sebagai pengambil keputusan berfungsi memerintahkan pelaksanaanya kepada orang-orang yang dipimpinya".

Berkaitan dengan fungsi intruktif, Kepala Desa Kelapapati memiliki kemampuan untuk membentukan pekerjaan dan tanggung jawab kepada aparaturnya dan memberikan pengaruh terhadap pembangunan di Desa Kelapapati. Berbagai strategi yang diterapkan seperti mengawasi pelaksanaan kerja sesuai perintah yang diberikan untuk meminimalisir resiko dan kesalahan serta memberikan manfaat dalam penyelenggaraan pemerintahan Desa. Hal ini sesuai dengan pendapat penelitian yang sama dalam melihat fungsi intruktif disammpaikan oleh (Hidayat, 2017) dalam penelitiannya mengatakan bahwa fungsi instruktif lebih kepada mengarahkan bagaimana cara mengerjakan suatu perintah, waktu pelaksanaan, laporan dan penempatan perintah tersebut dillaksanakan. Sedangkan fungsi intruktif dalam penelitian Efendi, Darmawi \& Noviyanto (2019) mengatakan ketegasan seorang pemimpin dalam memberikan intruksi dan selalu menjalankan peraturan sesuai standar yang ditetapkan. Hal ini berfungsi agar suatu pekerjaan yang diberikan oleh pegawai tidak bergeser jauh dari tugas dan fungsinya.

\section{Fungsi Konsultatif}

Kepala Desa dalam kepemimpinan juga merupakan sebagai tempat konsultasi dalam penyelesaian masalah desa dan masyarakat desa yang menurut Pasalong (2008) “ Fungsi kepemimpinan yang bersifat dua arah kepada yang dipimpinnya, meskipun pelaksanaan sangat tergantung pada pihak pemimpin. Ketika pemimpin akan mengambil suatu keputusan biasanya memerlukan beberapa pertimbangan yang mengharuskan berkonsultasi dengan orang-orang yang dipimpinnya".

Berkaitan dengan fungsi konsultatif, Kepala desa kelapapati memberikan kesempatan untuk menyampaikan pendapat, saran, ide dari masyarakat dan aparatur desa. Hal itu dilakukan guna penyempurnaan yang telah dibuat. Fungsi konsultatif sebenarnya dapat dilakukan dengan memberikan follow up kepada pegawai sehingga permasalahan yang dikerjakan dapat segera diatasi (Efendi, Darmawi \& Noviyanto (2019). Namun hal ini juga akan berjalan dengan baik jika pegawai bersifat terbuka (Hidayat, 2017).

\section{Fungsi Pastisipatif}

Kepala desa mempunyai fungsi partisipatif dalam mengarahkan, mengajak, dan ikut terlibat langsung dalam kegiatan pemerintahan desa dan masyarakat desa karena Pasalong (2008) mengatakan " fungsi kepemimpinan yang bersifat dua arah kepada yang dipimpinnya, tetapi juga berwujud pelaksanaan hubungan manusia yang efektif antara pemimpin dan yang dipimpin. Dalam fungsi ini pemimpin berusaha mengaktifkan orangorang yang dipimpinnya, baik dalam keikutsertaan mengambil keputusan maupun dalam melaksanakan keputusan". Berkaitan dengan fungsi partisipatif, Kepala desa Kelapapati melibatkan aparatur dan lembaga-lembaga desa dalam mengambil keputusan yang berkaitan dengan kegiatan masyarakat serta mengembangkan komunikasi antara aparatur, lembagalembaga desa dan masyarakat di desa kelapapati. Kepala desa juga ikut serta dalam proses pelaksanaan kegiatan yang telah di laksanakan. Hal ini sesuai dengan temuan dari (Efendi, 
Darmawi \& Noviyanto ,2019) dimana mengatakan bahwa partisipasi yang dilakukan oleh seluruh aparatur desa bukan hanya dilakukan secara internal, namun juga dilakukan eksternal. Melibatkan seluruh unsur dalam setiap hal, baik dalam proses pengambilan keputusan dan pelaksanaan kegiatan, sehingga seluruhnya memiliki peran penting dalam upaya pelayanan pemerintahan di desa (Gunawan, 2020).

4. Fungsi Delegasi

Pasalong (2008) mengatakan " fungsi pemimpin untuk mendelegasikan wewenang untuk membuat, menetapkan, dan atau melaksanakan keputusan, baik melalui persetujuan maupun tanpa persetujuan pimpinan. Fungsi ini mengharuskan pemimpin memilah-milah tugas pokok organisasi dan mengevaluasi yang dapat dan tidak dapat didelegasikan kepada orang-orang yang dipercayainya". Fungsi delegasi yang dilakukan oleh kepala desa kelapapati ialah bertanggung jawab terhadap apa yang telah dilimpahkan dan mengkondisikan pelimpahan wewenang yang telah ia berikan. Kepala desa telah memberikan kepercayaan kepada seluruh aparatur untuk dapat membantu kepala desa dalam menjalankan pemerintahan. Hal ini dinilai telah tepat dilakukan, jika meninjau dari hasil temuan (Hidayat, 2017) mengatakan bahwa belum optimal melakukan pelimpahan wewenangnya dikarenakan kemampuan serta tanggungjawan aparatur yang belum baik. Berbeda dengan temuan (Gunawan, 2020) mengatakan pelaksanaan Fungsi Delegasi sifatnya hanya situasional seperti pimpinan berada diluar kota atau aktifitas pemimpin saat tidak berada ditempat.

Dari semua variabel yang diteliti, telah didapati jawaban responden berkaitan dengan pelaksanaan fungsi kepemimpinan yang telah dilakukan oleh kepala desa Kelapapati. Dari kuesioner yang telah disebarkan, didapat skor sebagai berikut:

\begin{tabular}{lc}
\hline \multicolumn{1}{c}{ Variabel } & Skor \\
\hline Instruktif & 506 \\
\hline Konsultatif & 512 \\
\hline Partisipatif & 627 \\
\hline Delegasi & 620 \\
\hline Total & 2265
\end{tabular}

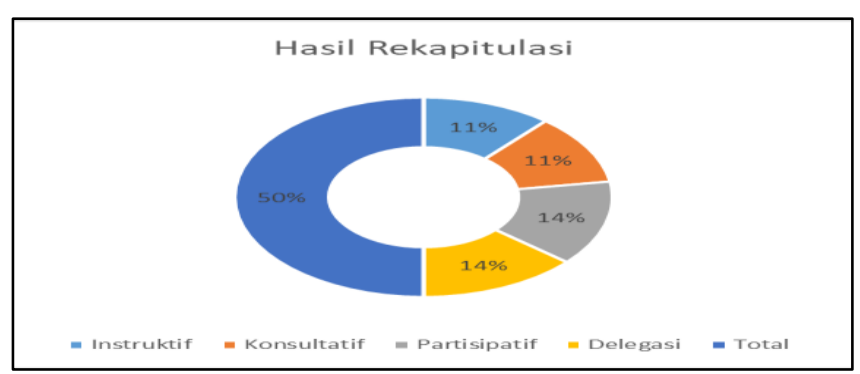

Dari total skor yang didapat, disimpulkan bahwa fungsi kepemimpinan berada di kategori Cukup Baik

\begin{tabular}{llr}
\hline Baik & $:$ & $2401-3600$ \\
\hline Cukup Baik & $:$ & $1201-2400$ \\
\hline Tidak Baik & $:$ & $0-1200$ \\
\hline
\end{tabular}

\section{Simpulan}

Pelaksanaan Fungsi Kepemimpinan kepala Desa Kelapapati dengan melihat 4 fungsi kepemimpinan yaitu fungsi instruktif, fungsi konsultatif, fungsi partisipatif dan fungsi delegasi dikatakan cukup baik. Untuk penelitian kedepan, disarankan untuk mencoba dengan metode kualitatif berkaitan dengan fungsi kepemimpinan kepala desa, agar mendapatkan 
informasi yang lebih dalam dan hasil yang ditemukan dapat menjadi referensi untuk keberlanjutan ilmu pengetahuan khususnya dalam fungsi kepemimpinan desa.

\section{Referensi}

Buku penulis tunggal

Fahmi, I. (2012). Manajemen Kepemimpinan Teori dan Aplikasi. Bandung: Alfabeta.

Kartono, K. (2005). Pemimpin dan Kepemimpinan, Cetakan Kedelapan, Penerbit PT. Raja Grafindo Persada, Jakarta. (Cetakan Ke). Jakarta: PT. Raja Grafindo Persada.

Kumar, R. (2019). Research Methodology-Fifth Edition. a step-by-step guide for beginners. (3, Ed.). London: SAGE Publication. Ltd.

Pasalong, H. (2008). Kepimpinan Birokrasi. Bandung: Alfabeta.

Artikel Jurnal:

Amrulloh, A. M. karim, \& Pramusinto, H. (2017). Pengaruh Kepemimpinan Kepala Desa, Fasilitas Kantor, Dan Kompensasi Terhadap Kinerja Se-Kecamatan Sukorejo. Economic Education Analysis Journal, 6(3), 912-922.

Efendi, S., Darmawi, E., \& Noviyanto, H. (2019). Fungsi Kepemimpinan Dalam Meningkatkan Prestasi Kerja Pegawai Kantor Camat Kedurang Kabupaten Bengkulu Selatan. Jurnal Penelitian Sosial Dan Politik, 8(1), 48-54.

Gunawan, M. A. (2020). No Fungsi Kepemimpinan Kepala Desa Dalam Meningkatkan Pelayanan Aparat Pada Masyarakat Di Desa Kali Baru Kecamatan Poleang Selatan Kabupaten Bombana. Jurnal Pemikiran Dan Penelitian Sosiologi, 7(1).

Harfis, Sopyan, \& Afrizal, D. (2019). Faktor penghambat partisipasi masyarakat dalam pembangunan desa. Jurnal Administrasi Publik Dan Bisnis, 1(2), 30-37.

Hidayat, S. (2017). Analisis Fungsi Kepemimpinan (Studi Kasus Pada Kantor Sekretariat DPRD Kota Lubuk Linggau). Jurnal Media Ekonomi (JURMEK), 22(3), 33-36.

Lamangida, T., Akbar, M. F., \& Hasan, H. (2017). Publik Jurnal Ilmu Administrasi. Jurnal Ilmu Administrasi, 6(1), 69-77.

Mahayana, W. (2013). Peran Kepala Desa Dalam Meningkatkan Kecamatan Kaubun Kabupaten. Ilmu Pemerintahan, 1(1), 400-414.

Nurhasanah. (2018). Nilai-Nilai Lokal dalam Kepemimpinan Kepala Desa di Desa Tanarigella Kecamatan Bua Kabupaten Luwu. Government: Jurnal Ilmu Pemerintahan, $11(1), 1-7$.

Syafitri, I., \& Suriani, L. (2019). Peran Kepemimpinan Kepala Desa Dalam Pelaksanaan Pembangunan Di Desa Sejati Kecamatan Rambah Hilir Kabupaten Rokan Hulu. Publika, 5(1), 44-54.

Yanuar, K. N., \& Dandang Setyawanti. (2017). Pengaruh Kepemimpinan Kepala Desa Dan Kesadaran Wajib Pajak Terhadap Kepatuhan Wajib Pajak Dalam Membayar Pajak Bumi Dan Bangunan Di Desa Candirejo, Kecamatan Ngawen, Kabupaten Klaten. Kiat Bisnis, 6(5), 461-469.

Artikel dalam internet:

Indonesia, R. Undang-Undang Republik Indonesia Nomor 6 Tahun 2014, Republik Indonesia 
$\S$ (2014). Indonesia. https://doi.org/10.1145/2904081.2904088

Manua, G., Sumampow, I., \& Kasenda, V. (2017). Efektivitas Kepemimpinan Kepala Desa Dalam Pembinaan Kemasyarakatan Di Desa Klabat Kecamatan Dimembe Kabupaten Minahasa Utara. Jurnal Eksekutif, $1(1), \quad$ 1-10. https://doi.org/10.1017/CBO9781107415324.004

Syofian, \& Ricky, H. T. (2019). Villagers' Satisfaction Indicators on Village Information System in The Front Region. Jurnal Niara, 12(2), 34-43. https://doi.org/10.31849/niara.v12i2.3072 